\title{
Short communication: Fourier-transform mid-infrared spectroscopy to predict coagulation and acidity traits of sheep bulk milk
}

\author{
C. L. Manuelian, ${ }^{1 *}$ M. Penasa, ${ }^{1}$ G. Giangolini, ${ }^{2}$ C. Boselli, ${ }^{2}$ S. Currò, ${ }^{1}$ and M. De Marchi ${ }^{1}$ \\ ${ }^{1}$ Department of Agronomy, Food, Natural Resources, Animals and Environment (DAFNAE), University of Padova, Viale dell'Università 16 , \\ 35020 Legnaro (PD), Italy \\ ${ }^{2}$ Istituto Zooprofilattico Sperimentale del Lazio e della Toscana "M. Aleandri"-National Reference Centre for Ovine \\ and Caprine Milk and Dairy Products Quality (CReLDOC), Via Appia Nuova 1411, 00178 Rome, Italy
}

\section{ABSTRACT}

Sheep milk is mainly transformed into cheese; thus, the dairy industry seeks more rapid and cost-effective methods of analysis to determine milk coagulation and acidity traits. This study aimed to assess the feasibility of Fourier-transform mid-infrared spectroscopy to determine milk coagulation and acidity traits of sheep bulk milk and to classify milk samples according to their renneting capacity. A total of 465 bulk milk samples collected in 140 single-breed flocks of Comisana (84 samples, 24 flocks) and Sarda (381 samples, 116 flocks) breeds located in Central Italy were analyzed for coagulation properties (rennet coagulation time, curd firming time, and curd firmness) and acidity traits ( $\mathrm{pH}$ and titratable acidity) using standard laboratory procedures. Fourier-transform mid-infrared spectroscopy prediction models for these traits were built using partial least squares regression analysis and were externally validated by randomly dividing the full data set into a calibration set $(75 \%)$ and a validation set $(25 \%)$. The discriminant capacity of the rennet coagulation time prediction model was determined using partial least squares discriminant analysis. Prediction models were more accurate for acidity traits than for milk coagulation properties, and the ratio of prediction to deviation ranged from 1.01 (curd firmness) to $2.14(\mathrm{pH})$. Moreover, the discriminant analysis led to an overall accuracy of 74 and $66 \%$ for the calibration and validation sets, respectively, with greater sensitivity for samples that coagulated between 10 and $20 \mathrm{~min}$ and greater specificity to detect early-coagulating $(<10$ min) and late-coagulating (20-30 min) samples. Results suggest that Fourier-transform mid-infrared spectroscopy has the potential to help the dairy sheep industry identify milk with better coagulation ability for cheese production and thus improve milk transformation ef-

Received June 21, 2018.

Accepted November 11, 2018.

*Corresponding author: carmenloreto.manuelianfuste@unipd.it ficiency. However, further research is needed before this information can be exploited at the industry level.

Key words: cheese, Comisana, milk quality, Sarda

\section{Short Communication}

In the European Union, sheep milk is the second most produced after bovine milk $\left(3.00 \times 10^{6}\right.$ and $215.69 \times 10^{6} \mathrm{t}$ in 2016 , respectively). Italy is the fourth most productive country, with a share of $14.14 \%$ in 2016 (FAOSTAT, 2018). Almost all sheep milk in the European Union is transformed into cheese due to the wide tradition in cheese manufacturing and the intrinsic milk composition (i.e., greater contents of protein, casein, fat, $\mathrm{Ca}, \mathrm{Mg}$, and $\mathrm{P}$ compared with cow and goat milk; Balthazar et al., 2017). In 2014, Italy contributed $16.85 \%\left(57.60 \times 10^{3} \mathrm{t}\right)$ of the European cheese production from sheep milk (FAOSTAT, 2018).

Milk technological traits such as milk coagulation properties (MCP) and acidity are difficult to measure during routine milk recording activities, mainly because their analysis is time consuming and expensive (De Marchi et al., 2014). Thus, the dairy industry is interested in the development of Fourier-transform midinfrared (FT-MIR) spectroscopy prediction models to quickly assess the ability of milk to be transformed into cheese. Moreover, the FT-MIR prediction models developed on individual cow milk have shown their potential for use in studies at the population level to describe breed differences (Penasa et al., 2014; Visentin et al., 2017a) and genetic evaluation for MCP (Tiezzi et al., 2013; Visentin et al., 2017b). Traditional MCP and acidity traits (McMahon and Brown, 1982) are rennet coagulation time (RCT; min), curd-firming time $\left(\mathbf{k}_{\mathbf{2 0}} ; \mathbf{m i n}\right)$, curd firmness 30 min after rennet addition to milk $\left(\mathbf{a}_{\mathbf{3 0}} ; \mathrm{mm}\right), \mathrm{pH}$, and titratable acidity (TA; Soxhlet-Henkel degrees/100 mL). Most studies on milk composition and technological characteristics of sheep milk have been carried out on individual samples to identify factors affecting these features (Sevi et al., 2000, 2004; Casamassima et al., 2001; Albenzio et al., 
2004; Abdelgawad et al., 2016), and results showed that breed, parity, stage of lactation, udder health, SCC, feeding strategies, and lambing season were important sources of variation. Other studies performed at the individual level (Manca et al., 2016; Puledda et al., 2017) estimated low to moderate correlations $(0.21-0.41$ in absolute value) of $\mathrm{RCT}, \mathrm{k}_{20}, \mathrm{a}_{30}$, and $\mathrm{pH}$ with cheese yield, all being positive except for $\mathrm{a}_{30}$.

Although FT-MIR prediction models for MCP have been investigated in individual cows (De Marchi et al., 2009; Toffanin et al., 2015; Calamari et al., 2016), buffalo (Manuelian et al., 2017), and Sarda milk ewes (Ferragina et al., 2017), to our knowledge no studies have assessed the feasibility of using FT-MIR spectroscopy to predict technological characteristics, including acidity traits, of sheep bulk milk. Therefore, the aim of the present study was to determine whether FTMIR spectroscopy can be used to predict sheep bulk milk coagulation and acidity traits and to classify milk samples on the basis of their renneting capacity.

Comisana and Sarda are among the most important sheep breeds in the Mediterranean area, especially in Italy, where they represent about $50.83 \%$ of the national sheep population (Ministero della Salute, 2018); they have an average lactation length of 182 and 168 $\mathrm{d}$ and a milk yield of 0.83 and $1.36 \mathrm{~kg} / \mathrm{d}$, respectively (Ferro et al., 2017). A total of 465 bulk milk samples were collected during a routine milk quality payment program in 140 single-breed flocks of Comisana (84 samples, 24 flocks) and Sarda (381 samples, 116 flocks) breeds located in Central Italy. The average number of samples per flock was $3.32(\mathrm{SD}=1.36)$, ranging from 1 to 9. Samples were collected between January and April 2014 after morning milking (representative of evening and morning milking), refrigerated $\left(4^{\circ} \mathrm{C}\right)$, and transported to the Experimental Zooprophylactic Institute of Lazio and Tuscany "Mariano Aleandri" (Rome, Italy) for milk chemical composition, SCC, milk acidity, and MCP determination. Briefly, a MilkoScan FT6000 (Foss Electric, Hillerød, Denmark) calibrated with appropriate sheep standards was used to determine fat, protein, casein, and lactose percentages, and a Fossomatic FC (Foss Electric) was used to determine $\mathrm{SCC}$. The $\mathrm{pH}$ was measured by a potentiometric $\mathrm{pH}$ meter (Mettler Delta 345; Mettler Toledo SpA, Novate Milanese, Italy), and TA was recorded in Soxhlet-Henkel degrees using a Crison Compact D meter (Crison Instruments SA, Alella, Spain) by tritating milk with a $0.25 \mathrm{~N} \mathrm{NaOH}$ solution until a $\mathrm{pH}$ of 8.30. A formagraph (Foss Electric) was used to measure MCP: milk samples $(10 \mathrm{~mL})$ were heated to $35^{\circ} \mathrm{C}$, and $200 \mu \mathrm{L}$ of calf rennet $(25 \%$ chymosin and $75 \%$ bovine pepsin; 175 international milk clotting units/mL; Caglificio Clerici Spa-Sacco Srl, Cadorago, Italy) diluted to $0.8 \%$ (wt/ wt) in distilled water was added to milk. The analysis lasted 30 min after the addition of the enzyme. Values that deviated more than 3 standard deviations from the respective mean of each trait and breed were treated as missing values; this resulted in 1 missing value for $\mathrm{a}_{30}, 2$ for lactose and TA, and 3 for $\mathrm{pH}$ in the Comisana breed and 1 missing value for protein, 2 for $\mathrm{k}_{20}, 3$ for $\mathrm{pH}, 5$ for fat, lactose, and TA, and 15 for $\mathrm{a}_{30}$ in the Sarda breed.

The spectral information of milk samples (1,060 data points; region from 5,000 to $900 \mathrm{~cm}^{-1}$ ) from a MilkoScan FT6000 (Foss Electric) was matched with the reference values of $\mathrm{RCT}, \mathrm{k}_{20}, \mathrm{a}_{30}, \mathrm{pH}$, and TA. Low signal-to-noise ratio spectral regions $\left(3,690\right.$ to $2,990 \mathrm{~cm}^{-1}$ and 1,680 to $1,580 \mathrm{~cm}^{-1}$ ) were discarded before building the calibration models. Prediction models were developed through partial least squares regression analysis using the pls package (Mevik et al., 2016) in $\mathrm{R}$ version 3.4.4 (R Core Team, 2018). The data set was randomly divided into a calibration set ( $75 \%$ of the observations) and a validation set (25\% of the observations). The equality of means and variances of both sets was tested for each trait using a $t$-test and $F$-test, respectively. Means and variation of the validation data set were very similar to those of the calibration data set. In the calibration set, leave-one-out cross-validation was performed. The optimal number of models factors was determined as the minimum number of factors to achieve the lowest root mean squared error of prediction. The goodness-of-fit statistics considered were the coefficient of determination of cross-validation and external validation $\left(\mathbf{R}^{2} \mathbf{C V}\right.$ and $\mathbf{R}_{\mathrm{ExV}}^{2}$, respectively) and the root mean squared error of prediction of cross-validation and external validation. In the validation set, the ratio of prediction to deviation (RPD) was calculated as the ratio of the standard deviation of the trait to the root mean squared error of prediction of external validation (Williams, 2007), and bias was calculated as the average difference between the reference value and the respective predicted value for each observation. Moreover, in the validation set, reference values of each model were linearly regressed on the respective predicted value to obtain the linear regression coefficient (slope). A $t$-test was used to determine whether the bias and slope were statistically different from zero and 1, respectively. To evaluate the capacity of FT-MIR spectroscopy to classify bulk milk according to its coagulation ability, milk samples were stratified into 3 classes based on their RCT, following the approach of Manuelian et al. (2017) for buffalo milk samples: early coagulating $(\mathrm{RCT} \leq 10 \mathrm{~min})$, mid coagulating $(10 \mathrm{~min}<\mathrm{RCT} \leq 20$ min), and late coagulating ( $20 \mathrm{~min}<\mathrm{RCT} \leq 30 \mathrm{~min}$ ). Partial least squares discriminant analysis (PLS-DA) was then performed on the calibration set and tested on the validation set using the DiscriMiner package of $R$ 
Table 1. Descriptive statistics of bulk milk technological and composition traits

\begin{tabular}{|c|c|c|c|c|c|c|c|c|c|}
\hline Trait $^{1}$ & \multicolumn{3}{|c|}{ Overall } & \multicolumn{3}{|c|}{ Comisana } & \multicolumn{3}{|c|}{ Sarda } \\
\hline \multicolumn{10}{|c|}{ Milk coagulation traits } \\
\hline $\mathrm{k}_{20}, \min$ & 463 & $2.26(0.55)$ & 4.85 & 84 & $2.14(0.54)$ & 2.15 & 379 & $2.29(0.55)$ & 4.70 \\
\hline $\mathrm{a}_{30}, \mathrm{~mm}$ & 449 & $49.54(7.96)$ & 43.10 & 83 & $49.90(9.18)$ & 43.10 & 366 & $49.49(7.66)$ & 40.20 \\
\hline \multicolumn{10}{|l|}{ Milk acidity } \\
\hline Fat & 460 & $6.37(0.81)$ & 5.18 & 84 & $6.93(0.87)$ & 3.80 & 376 & $6.24(0.75)$ & 4.88 \\
\hline Protein & 464 & $5.76(0.37)$ & 2.01 & 84 & $6.12(0.36)$ & 1.46 & 380 & $5.68(0.32)$ & 1.73 \\
\hline Casein & 465 & $4.57(0.32)$ & 1.77 & 84 & $4.86(0.32)$ & 1.32 & 381 & $4.50(0.29)$ & 1.52 \\
\hline Lactose & 458 & $4.77(0.16)$ & 1.15 & 82 & $4.63(0.18)$ & 0.93 & 376 & $4.80(0.14)$ & 0.91 \\
\hline SCS & 465 & $6.07(0.35)$ & 2.41 & 84 & $6.23(0.19)$ & 0.92 & 381 & $6.03(0.37)$ & 2.41 \\
\hline
\end{tabular}

${ }^{1} \mathrm{RCT}=$ rennet coagulation time; $\mathrm{k}_{20}=$ curd-firming time; $\mathrm{a}_{30}=$ curd firmness 30 min after rennet addition to milk; TA $=$ titratable acidity; $\mathrm{SH}^{\circ}=$ Soxhlet-Henkel degree.

${ }^{2}$ Range $=$ maximum value - minimum value.

(Sanchez, 2013), and the performance of the model was assessed by calculating sensitivity, specificity, accuracy, balanced accuracy, and balanced error rate.

Descriptive statistics showed that all bulk milk samples coagulated within $30 \mathrm{~min}$ from rennet addition, which differed from the scenario of other studies on individual buffalo (Manuelian et al., 2017), cow (Dal Zotto et al., 2008; Visentin et al., 2015), and Sarda sheep (Puledda et al., 2017) milks, which reported between 4.8 and $16.8 \%$ of noncoagulating samples. Fat and lactose percentages for Comisana and Sarda breeds (Table 1) were in agreement with milk composition of the same breeds reported in the meta-analysis of Ferro et al. (2017), although those authors reported a lower protein content (5.77 and $5.22 \%$ for Comisana and Sarda, respectively). Milk of Comisana ewes had greater fat, protein, and casein percentages, SCS, RCT, $\mathrm{a}_{30}$, and TA and lower lactose percentage, $\mathrm{k}_{20}$, and $\mathrm{pH}$ than milk of Sarda ewes (Table 1). However, due to the lower number of samples available for Comisana compared with Sarda and the fact that it is difficult to quantify environmental factors using data from routine milk recording, a statistical comparison was not feasible to confirm breed differences. Indeed, the meta-analysis of Ferro et al. (2017) and the study of Claps et al. (2016) in bulk milk between Comisana and Sarda ewes reared in the same flock reported a similar milk composition for the 2 breeds. On the other hand, Duranti et al. (2003) observed a greater RCT and $\mathrm{k}_{20}$ in Comisana than in Sarda bulk milk and a similar $\mathrm{a}_{30}$. Using individual milk samples of the Sarda breed, Pazzola et al. (2014), Manca et al. (2016), and Ferragina et al. (2017) reported shorter RCT (from 8.62 to $13.39 \mathrm{~min}$ ) and $\mathrm{k}_{20}$ (from 1.75 to $1.95 \mathrm{~min}$ ) and greater $\mathrm{a}_{30}$ (from 50.00 to $54.99 \mathrm{~mm}$ ) compared with values in the present study. On the other hand, Puledda et al. (2017) reported a longer RCT (15.18 $\mathrm{min})$, shorter $\mathrm{k}_{20}(1.75 \mathrm{~min})$, and greater $\mathrm{a}_{30}(52.63 \mathrm{~mm})$. In sheep bulk milk, Duranti et al. (2003) reported a shorter RCT (4.78 and $4.21 \mathrm{~min}$, respectively), longer $\mathrm{k}_{20}$ (3.40 and 2.47 min, respectively), and lower $\mathrm{a}_{30}$ (35.67 and 35.84 $\mathrm{mm}$, respectively) compared with values in the present study. Possible explanations for the differences between our results and those of Pazzola et al. (2014), Manca et al. (2016), Ferragina et al. (2017), and Puledda et al. (2017) are the greater chymosin proportion (80\%) in the rennet used for MCP analysis in the mentioned studies and the different dilution $(1.2 \%$; wt/wt) in the case of Pazzola et al. (2014) and Ferragina et al. (2017). On the other hand, Duranti et al. (2003) used freezedried samples that were reconstituted for the MCP determination instead of analyzing fresh milk.

Fitting statistics of the predicted models for MCP and acidity are presented in Table 2 . To our knowledge, this is the first study to investigate the potential of FT-MIR spectroscopy to predict MCP and acidity in sheep bulk milk. Taking this issue into account, the comparison and discussion of the results regarding the same predicted traits is based on other species or individual milk samples. For all traits, the bias in the validation set did not differ from zero, and the slope of the linear regression of predicted on measured values differed from unity $(P<0.05)$. The greatest $\mathrm{R}_{\text {ExV }}^{2}$ and $\mathrm{RPD}$ in external validation were reached for milk $\mathrm{pH}$ (0.77 and 2.14, respectively) and milk TA (0.66 and 1.72 , respectively), and the lowest $\mathrm{R}_{\mathrm{ExV}}^{2}$ and $\mathrm{RPD}$ were reached for $\mathrm{a}_{30}(0.02$ and 1.01 , respectively). Ferragina et al. (2017) reported a greater $\mathrm{R}_{\mathrm{ExV}}^{2}(0.63-0.83)$ for MCP in individual milk samples of Sarda ewes; however, they did not report the RPD statistics. Compared 
with our findings, Manuelian et al. (2017) obtained slightly greater $\mathrm{R}_{\text {ExV }}^{2}(0.27-0.35)$ and $\mathrm{RPD}(1.17-1.20)$ in external validation for MCP and similar $\mathrm{R}_{\mathrm{ExV}}^{2}(0.66-$ $0.76)$ and slightly lower RPD (1.71-2.08) in external validation for the acidity traits in individual buffalo milk. In individual cow milk, Dal Zotto et al. (2008) reported greater $\mathrm{R}_{\mathrm{CV}}^{2}$ and $\mathrm{RPD}$ in cross-validation for RCT (0.63 and 1.62, respectively) and $\mathrm{a}_{30}$ (0.45 and 1.34, respectively), whereas De Marchi et al. (2009) obtained a comparable $\mathrm{R}_{\mathrm{CV}}^{2}$ for TA and $\mathrm{pH}$ (0.81 and 0.77 , respectively), and Visentin et al. (2015) calculated a slightly greater $\mathrm{R}_{\mathrm{ExV}}^{2}(0.46-0.55)$ and RPD in external validation $(1.35-1.49)$ for MCP. However, FT-MIR prediction models for MCP developed by the aforementioned authors reached an RPD that was less than 2.5, which is the minimum value commonly recommended to consider a prediction model fair enough for screening purposes (Williams, 2014). As a secondary method, FT-MIR prediction model accuracy is directly affected by the analytical error (De Marchi et al., 2014). Therefore, the low accuracy (i.e., low $\mathrm{R}_{\mathrm{CV}}^{2}, \mathrm{R}_{\mathrm{ExV}}^{2}$, and RPD) of the proposed FT-MIR prediction models for MCP traits could be due to the lower instrumental repeatability and reproducibility of the MCP determination in the laboratory compared with milk composition traits, as previously suggested by Duranti et al. (2003), Penasa et al. (2015), and Ferragina et al. (2017).

Although the RPD in external validation achieved for RCT was lower than 2.5, we decided to go ahead with the PLS-DA analysis because the thresholds to interpret RPD depend on the application of the prediction models, the complexity of the matrix analyzed, and the difficulties with the reference analysis (Williams, 2014). Moreover, Manuelian et al. (2017) showed the feasibility of performing a rough screening in buffalo milk based on a prediction model for RCT with an RPD in external validation of 1.19 , which is similar to the one obtained in our study. Results of the PLS-DA analysis conducted to assess the capability of the prediction model to correctly classify milk samples according to their coagulation ability are displayed in Table 3. About $62 \%$ of the samples in the calibration and validation sets were originally classified as mid coagulating, $22 \%$ as early coagulating, and $16 \%$ as late coagulating. The greater number of samples in the mid-coagulating class agreed with the average value of RCT (Table 1). The distribution of samples across RCT classes was similar to that reported by Manuelian et al. (2017) using individual buffalo milk, where $45 \%$ of milks were classified as mid coagulating, $26 \%$ as early coagulating, and $14 \%$ as late coagulating. Those authors also had a class for the samples that did not coagulate within $30 \mathrm{~min}$ (17\% of the samples). The overall accuracy of the PLS-DA model to assign samples to the correct

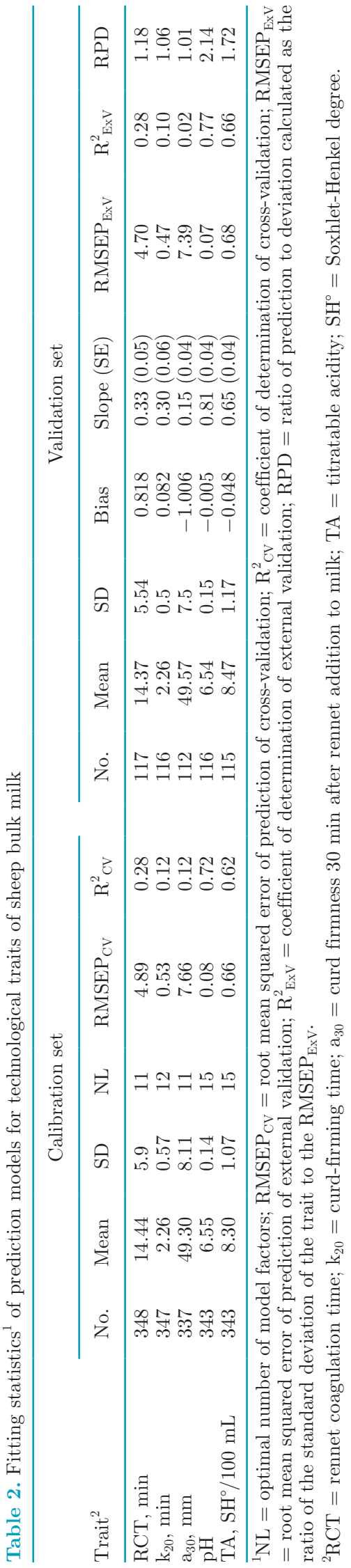


Table 3. Confusion matrix and statistical measures of performance of the partial least squares discriminant analysis (PLS-DA) model for the classification of milk coagulation ability based on 3 thresholds of rennet coagulation time $(\mathrm{RCT})^{1}$ in bulk milk samples ${ }^{2}$

\begin{tabular}{|c|c|c|c|c|c|c|}
\hline \multirow[b]{2}{*}{ Item } & \multicolumn{3}{|c|}{ Calibration set $(\mathrm{n}=348)$} & \multicolumn{3}{|c|}{ Validation set $(\mathrm{n}=117)$} \\
\hline & Early & Mid & Late & Early & Mid & Late \\
\hline \multicolumn{7}{|l|}{ Predicted original } \\
\hline Early & 39 & 34 & 3 & 8 & 16 & 2 \\
\hline Mid & 6 & 210 & 5 & 2 & 65 & 4 \\
\hline Late & 2 & 39 & 10 & 0 & 16 & 4 \\
\hline \multicolumn{7}{|l|}{ Model performance, $\%$} \\
\hline Sensitivity & 51.32 & 95.02 & 19.61 & 30.77 & 91.55 & 20.00 \\
\hline Specificity & 97.06 & 42.52 & 97.31 & 97.98 & 30.43 & 93.81 \\
\hline Accuracy & 87.07 & 75.86 & 85.92 & 82.91 & 67.53 & 81.20 \\
\hline Balanced accuracy & 85.34 & 78.64 & 71.57 & 81.59 & 68.51 & 62.52 \\
\hline Balanced error rate & 14.66 & 21.36 & 28.43 & 18.41 & 31.49 & 37.48 \\
\hline Overall accuracy & & 74.43 & & & 65.81 & \\
\hline
\end{tabular}

${ }^{1}$ Early $(\mathrm{RCT} \leq 10 \mathrm{~min})$, mid $(10 \mathrm{~min}<\mathrm{RCT} \leq 20 \mathrm{~min})$, and late $(20 \mathrm{~min}<\mathrm{RCT} \leq 30 \mathrm{~min})$ coagulating.

${ }^{2}$ The PLS-DA model was trained in the calibration data set and tested on the validation data set. Values in bold indicate the number of correctly classified samples.

original class of milk coagulation ability was slightly lower in the validation set $(65.81 \%)$ than in the calibration set $(74.43 \%$; Table 3$)$. This agreed with Manuelian et al. (2017), who also reported a lower accuracy in the calibration set than in the validation set in buffalo milk. The measures of performance of the model within each class showed that the calibration and validation sets performed similarly (Table 3 ). The ability to detect true positive (sensitivity) was high for mid-coagulating samples, moderate for early-coagulating samples, and low for late-coagulating samples. On the other hand, the PLS-DA model showed the highest specificity (true negative) for early- and late-coagulating samples and a moderate specificity for mid-coagulating samples. The accuracy of the model was higher for the early- and late-coagulating group than for the mid-coagulating group. However, the unbalanced number of samples in each class could have affected the sensitivity and specificity, leading to biased results. Thus, the balanced accuracy was calculated and results revealed a slight decrease in accuracy for the early- and latecoagulating samples and a slight increase in accuracy for the mid-coagulating samples. On the basis of the balanced accuracy, the prediction model could better detect early-coagulating samples than mid- and latecoagulating samples. These findings were comparable with those observed in buffalo milk, where the highest number of correctly classified samples was observed for early-coagulating and noncoagulating milks and the lowest for mid- and late-coagulating milks (Manuelian et al., 2017).

In conclusion, in agreement with previous studies on prediction equations for MCP and acidity traits of buffalo and bovine milk, FT-MIR spectroscopy cannot replace the reference laboratory methods due to the moderate to low accuracy of prediction. Nevertheless, the discriminant analysis revealed that FT-MIR spectra contained interesting information on MCP to make FT-MIR spectroscopy a tool for screening purposes to discriminate between early-, mid-, and late-coagulating milk. Further research is needed before this information can be exploited at the industry level to identify bulk milk with coagulation characteristics suitable for cheese production to improve milk transformation efficiency.

\section{ACKNOWLEDGMENTS}

This paper is based on the research project CUP: G83118000070001, funded by the Italian Ministry of Health (Rome, Italy).

\section{REFERENCES}

Abdelgawad, A. R., M. Rovai, G. Caja, G. Leitner, and M. Castillo. 2016. Evaluating coagulation properties of milk from dairy sheep with subclinical intramammary infection using near infrared light scatter. J. Food Eng. 168:180-190.

Albenzio, M., M. Caroprese, A. Santillo, R. Marino, L. Taibi, and A. Sevi. 2004. Effects of somatic cell count and stage of lactation on the plasmin activity and cheese-making properties of ewe milk. J. Dairy Sci. 87:533-542.

Balthazar, C. F., T. C. Pimentel, L. L. Ferrão, C. N. Almada, A. Santillo, M. Albenzio, N. Mollakhalili, A. M. Mortazavian, J. S. Nascimento, M. C. Silva, M. Q. Freitas, A. S. Sant'Ana, D. Granato, and A. G. Cruz. 2017. Sheep milk: Physicochemical characteristics and relevance for functional food development. Compr. Rev. Food Sci. Food Saf. 16:247-262.

Calamari, L., L. Gobbi, and P. Bani. 2016. Improving the prediction ability of FT-MIR spectroscopy to assess titratable acidity in cow's milk. Food Chem. 192:477-484.

Casamassima, D., A. Sevi, M. Palazzo, R. Ramacciato, G. E. Colella, and A. Bellitti. 2001. Effects of two different housing systems on behavior, physiology and milk yield of Comisana ewes. Small Rumin. Res. 41:151-161.

Claps, S., G. Annicchiarico, M. A. Di Napoli, F. Paladino, D. Giorgio, L. Sepe, R. Rossi, and A. Di Trana. 2016. Native and non-native 
sheep breed differences in canestrato pugliese cheese quality: A resource for a sustainable pastoral system. Czech J. Food Sci. $34: 332-340$.

Dal Zotto, R., M. De Marchi, A. Cecchinato, M. Penasa, M. Cassandro, P. Carnier, L. Gallo, and G. Bittante. 2008. Reproducibility and repeatability of measures of milk coagulation properties and predictive ability of mid-infrared reflectance spectroscopy. J. Dairy Sci. 91:4103-4112.

De Marchi, M., C. C. Fagan, C. P. O'Donnell, A. Cecchinato, R. Dal Zotto, M. Cassandro, M. Penasa, and G. Bittante. 2009. Prediction of coagulation properties, titratable acidity, and $\mathrm{pH}$ of bovine milk using mid-infrared spectroscopy. J. Dairy Sci. 92:423-432.

De Marchi, M., V. Toffanin, M. Cassandro, and M. Penasa. 2014 Invited review: Mid-infrared spectroscopy as phenotyping tool for milk traits. J. Dairy Sci. 97:1171-1186.

Duranti, E., P. Bolla, A. Caroli, L. Chiofalo, L. Di Stasio, R. Fortina, M. Martini, V. Piccolo, and A. Zullo. 2003. Problems concerning ovine milk clotting aptitude. Ital. J. Anim. Sci. 2:89-95.

FAOSTAT. 2018. Data. Accessed May 17, 2018. http://www.fao.org/ faostat/en/\#data.

Ferragina, A., C. Cipolat-Gotet, A. Cecchinato, M. Pazzola, M. L. Dettori, G. M. Vacca, and G. Bittante. 2017. Prediction and repeatability of milk coagulation properties and curd-firming modeling parameters of ovine milk using Fourier-transform infrared spectroscopy and Bayesian models. J. Dairy Sci. 100:3526-3538.

Ferro, M. M., L. O. Tedeschi, and A. S. Atzori. 2017. The comparison of the lactation and milk yield and composition of selected breeds of sheep. Transnat. Anim. Sci. 1:498-506.

Manca, M. G., J. Serdino, G. Gaspa, P. Urgeghe, I. Ibba, M. Contu, P. Fresi, and N. P. P. Macciotta. 2016. Derivation of multivariate indices of milk composition, coagulation properties, and individual cheese yield in dairy sheep. J. Dairy Sci. 99:4547-4557.

Manuelian, C. L., G. Visentin, C. Boselli, G. Giangolini, M. Cassandro, and M. De Marchi. 2017. Short communication: Prediction of milk coagulation and acidity traits in Mediterranean buffalo milk using Fourier-transform mid-infrared spectroscopy. J. Dairy Sci. 100:7083-7087.

McMahon, D. J., and R. J. Brown. 1982. Evaluation of formagraph for comparing rennet solutions. J. Dairy Sci. 65:1639-1642.

Mevik, B.-H., R. Wehrens, and K. H. Liland. 2016. pls: Partial Least Squares and Principal Component Regression. Package Version 2.6-0. Accessed May 9, 2018. https://CRAN.R-project.org/ package $=$ pls.

Ministero della Salute. 2018. Sistema Informativo Malattie Animali Nazionale. Accessed Jun. 13, 2018. https://www.vetinfo.sanita.it.

Pazzola, M., M. L. Dettori, C. Cipolat-Gotet, A. Cecchinato, G. Bittante, and G. M. Vacca. 2014. Phenotypic factors affecting coagulation properties of milk from Sarda ewes. J. Dairy Sci. 97:72477257.

Penasa, M., M. De Marchi, S. Ton, L. Ancilotto, and M. Cassandro. 2015. Reproducibility and repeatability of milk coagulation properties predicted by mid-infrared spectroscopy. Int. Dairy J. 47:1-5.
Penasa, M., F. Tiezzi, A. Sturaro, M. Cassandro, and M. De Marchi. 2014. A comparison of the predicted coagulation characteristics and composition of milk from multi-breed herds of Holstein-Friesian, Brown Swiss and Simmental cows. Int. Dairy J. 35:6-10.

Puledda, A., G. Gaspa, M. G. Manca, J. Serdino, P. P. Urgeghe, C. Dimauro, R. Negrini, and N. P. P. Macciotta. 2017. Estimates of heritability and genetic correlations for milk coagulation properties and individual laboratory cheese yield in Sarda ewes. Animal 11:920-928.

R Core Team. 2018. R: A Language and Environment for Statistical Computing. Accessed May 9, 2018. https://www.r-project.org/.

Sanchez, G. 2013. DiscriMiner: Tools of the Trade for Discriminant Analysis. Package Version 0.1-29. Accessed May 9, 2018. http:// CRAN.R-project.org/package=DiscriMiner.

Sevi, A., M. Albenzio, R. Marino, A. Santillo, and A. Muscio. 2004 Effects of lambing season and stage of lactation on ewe milk quality. Small Rumin. Res. 51:251-259.

Sevi, A., L. Taibi, M. Albenzio, A. Muscio, and G. Annicchiarico. 2000 Effect of parity on milk yield, composition, somatic cell count, renneting parameters and bacteria counts of Comisana ewes. Small Rumin. Res. 37:99-107.

Tiezzi, F., D. Pretto, M. De Marchi, M. Penasa, and M. Cassandro. 2013. Heritability and repeatability of milk coagulation properties predicted by mid-infrared spectroscopy during routine data recording, and their relationships with milk yield and quality traits. Animal 7:1592-1599.

Toffanin, V., M. De Marchi, N. Lopez-Villalobos, and M. Cassandro. 2015. Effectiveness of mid-infrared spectroscopy for prediction of the contents of calcium and phosphorus, and titratable acidity of milk and their relationship with milk quality and coagulation properties. Int. Dairy J. 41:68-73.

Visentin, G., M. De Marchi, D. P. Berry, A. McDermott, M. A. Fenelon, M. Penasa, and S. McParland. 2017a. Factors associated with milk processing characteristics predicted by mid-infrared spectroscopy in a large database of dairy cows. J. Dairy Sci. 100:3293-3304.

Visentin, G., A. McDermott, S. McParland, D. P. Berry, O. A. Kenny, A. Brodkorb, M. A. Fenelon, and M. De Marchi. 2015. Prediction of bovine milk technological traits from mid-infrared spectroscopy analysis in dairy cows. J. Dairy Sci. 98:6620-6629.

Visentin, G., S. McParland, M. De Marchi, A. McDermott, M. A. Fenelon, M. Penasa, and D. P. Berry. 2017b. Processing characteristics of dairy cow milk are moderately heritable. J. Dairy Sci. 100:6343-6355.

Williams, P. 2007. Near-Infrared Technology: Getting the Best Out of Light. PDK Grain, Nanaimo, BC, Canada.

Williams, P. 2014. The RPD statistic: A tutorial note. NIR News $25: 22-26$. 